Article

\title{
Perfluorination of Aromatic Compounds Reinforce Their van der Waals Interactions with Rare Gases: The Rotational Spectrum of Pentafluoropyridine-Ne
}

\author{
Alberto Macario ${ }^{1,+}\left(\mathbb{D}\right.$, Susana Blanco ${ }^{1}\left(\mathbb{D}\right.$, Ibon Alkorta ${ }^{2}$ (i) and Juan Carlos López ${ }^{1, *(1)}$ \\ 1 Departamento de Química Física y Química Inorgánica, Facultad de Ciencias, \\ IU CINQUIMA Universidad de Valladolid, 47011 Valladolid, Spain; alberto.macario@uva.es (A.M.); \\ susana.blanco@uva.es (S.B.) \\ 2 Instituto de Química Médica (CSIC), Juan de la Cierva 3, 28006 Madrid, Spain; ibon@iqm.csic.es \\ * Correspondence: juancarlos.lopeza@uva.es; Tel.: +34-983185891 \\ + Current Address: Département de Physique Moléculaire, IPR (Institut de Physique de Rennes), \\ CNRS-UMR 6251, Université de Rennes 1, F-35000 Rennes, France; alberto.macario@univ-rennes1.fr.
}

Citation: Macario, A.; Blanco, S.; Alkorta, I.; López, J.C. Perfluorination of Aromatic Compounds Reinforce Their van der Waals Interactions with Rare Gases: The Rotational Spectrum of Pentafluoropyridine-Ne. Molecules 2022, 27, 17. https://doi.org/ $10.3390 /$ molecules 27010017

Academic Editor: Weixing Li

Received: 8 November 2021

Accepted: 17 December 2021

Published: 21 December 2021

Publisher's Note: MDPI stays neutral with regard to jurisdictional claims in published maps and institutional affiliations.

Copyright: (C) 2021 by the authors. Licensee MDPI, Basel, Switzerland. This article is an open access article distributed under the terms and conditions of the Creative Commons Attribution (CC BY) license (https:// creativecommons.org/licenses/by/ $4.0 /)$.

\begin{abstract}
The rotational spectrum of the pentafluoropyridine-Ne complex, generated in a supersonic jet, has been investigated using chirped-pulse microwave Fourier transform spectroscopy in the 2-8 GHz range. The spectra of the ${ }^{20} \mathrm{Ne}$ and ${ }^{22} \mathrm{Ne}$ species have been observed, and the rotational constants have been used to determine the structure of the complex. This structure, and those of the previously experimentally studied complexes benzene- $\mathrm{Ne}$ and pyridine- $\mathrm{Ne}$, are an excellent benchmark for the theoretical calculations on these adducts. These complexes and hexafluorobenzeneNe have been investigated at the CCSD/6-311++G(2d,p) level. The calculations reproduce the experimental structures well and show how the van der Waals complexes are stronger for the perfluorinated compound.
\end{abstract}

Keywords: van der Waals interactions; rotational spectroscopy; structure; computational chemistry; fluorine aromatic compounds

\section{Introduction}

Supersonic jet expansions have been widely used to generate intermolecular complexes of diverse nature, which are studied by spectroscopic methods to characterize the noncovalent forces responsible for their formation. Fourier transform microwave spectroscopy (FTMW) combined with supersonic jets with reinforced high resolution and sensitivity [1-4] has contributed to the study of challenging molecular systems, including weakly bound molecular complexes [5]. This technique makes possible the unambiguous discrimination between different isomers, including tautomers, conformers, or isotopomers. The spatial mass distribution of such species has unique spectroscopic constants and distinct individual rotational spectra, a key feature that makes FTMW techniques powerful tools [6] in cases where other techniques may struggle. Complexes generated in supersonic expansions are isolated species that can be characterized in absence of intermolecular forces existing in condensed phases. This provides an ideal environment to investigate their intrinsic properties, structure, and interactions, which can be benchmarked with the results of theoretical calculations [7].

Aggregates formed by a molecule and a rare gas (RG) atom, generally that used to drive the expansion, have been studied to characterize the van der Waals interactions due to dispersion forces [8]. These forces have an important role in the stabilization of biological systems and materials [9], and have been also studied in complexes or rare gases present in the upper atmosphere with oxygen molecules in excited electronic states [10]. Aromatic rings offer a relatively large surface for dispersion interaction forces, so these kinds of molecules have often been used to model the interactions with rare gas atoms. Complexes 
of the prototype rings, benzene (BZ), with He [11], Ne [12,13], Ar [13,14], Kr [15], and Xe [13], or pyridine (PY), with He [16], Ne [17-20], Ar [19,21,22], and Kr [21], have been studied. Complexes of RG atoms with other six-membered ring aromatic molecules such as pyrimidine [23,24], pyridazine $[25,26]$, and fluorobenzene [27-29] or fluoropyridine [30] derivatives have also been characterized.

The structure of molecule-RG atom complexes has been investigated through the observation of the rotational spectra of different isotopologues, including those of RG atoms. Although those parameters are often affected by intermolecular vibrations, it has been possible to investigate the geometry of the heterodimers, which in the case of the benzene-RG complex corresponds to a $C_{6 \mathrm{v}}$ symmetry where the RG atom lies along the $C_{6}$ benzene symmetry axis $[13,14]$. For pyridine-RG complexes, the RG atom is above the ring plane but is considerably shifted towards the $\mathrm{N}$ atom [16-22]. The rotation of the RG atom to explore both sides of the ring would give rise to two equivalent forms; however, with the exception of $\mathrm{He}[11,16]$, the barriers hindering this flipping motion are high enough to prevent the observation of tunneling effects. In many cases, under the assumption that the RG stretching motion can be isolated from bending vibrations, the dissociation energies of these complexes have been estimated from the $\Delta_{\mathrm{J}}$ centrifugal distortion constants based on the pseudodiatomic approximation $[17,20,22-25]$. Additionally, in some cases, information about the bending motions has been obtained [24,31].

The complexes of perfluorinated aromatic rings such as hexafluorobenzene $\left(\mathrm{F}_{6} \mathrm{BZ}\right)$ or pentafluoropyridine ( $\left.\mathrm{F}_{5} \mathrm{PY}\right)$ with water [32,33] ammonia [34], and formaldehyde [35] have led to important conclusions about the changes induced by perfluorination in the aromatic $\pi$-cloud. The aromatic $\pi$-cloud acts, in general, as a Lewis base in noncovalent interactions. Fluorine atoms withdraw the electron density of the $\pi$-cloud region, creating a $\pi$-hole [36] which acts as a Lewis acid [37-40] that can interact with lone-pair-bearing atoms and enhance anion- $\pi$ interactions $[39,41,42]$. In fact, in the complexes of $\mathrm{F}_{6} \mathrm{BZ}_{\text {or }} \mathrm{F}_{5} \mathrm{PY}$ with water, ammonia, or formaldehyde, the $\mathrm{O}$ or $\mathrm{N}$ lone pairs of these small molecules point directly toward the center of the ring, showing the existence of lone-pair $\cdots \pi$-hole interactions. These interactions show almost equal contributions of electrostatic and dispersion forces [34,35], but the changes in the structures from $\mathrm{O}-\mathrm{H} \cdots \pi, \mathrm{N}-\mathrm{H} \cdots \pi$ in the $\mathrm{BZ}-\mathrm{H}_{2} \mathrm{O}$ or $\mathrm{BZ}-\mathrm{NH}_{3}$ or $\mathrm{N} \cdots \mathrm{C}=\mathrm{O}\left(\mathrm{n} \rightarrow \pi^{*}\right)$ in $\mathrm{PY}-\mathrm{CH}_{2} \mathrm{O}$ to the $\mathrm{H}_{2} \mathrm{O} \cdots \pi$-hole, $\mathrm{H}_{3} \mathrm{~N} \cdots \pi$-hole or $\mathrm{H}_{2} \mathrm{C}=\mathrm{O} \cdots \pi$-hole in $\mathrm{F}_{6} \mathrm{BZ}$ and $\mathrm{F}_{5} \mathrm{PY}$ complexes can probably be attributed mainly to electrostatic changes. An investigation of the effects of perfluorination on the $\pi$-cloud and their implications on the dispersion forces contributing to the formation of complexes has not been conducted. In this paper we characterized the structure of the complex $\mathrm{F}_{5} \mathrm{PY}-\mathrm{Ne}$ from the rotational spectrum. We compared the structure of this complex with previous experimental results on PY-Ne. Furthermore, a comparative study on the theoretically calculated energies and binding properties of BZ-Ne, PY-Ne, $\mathrm{F}_{6} \mathrm{BZ}-\mathrm{Ne}$ and $\mathrm{F}_{5} \mathrm{PY}-\mathrm{Ne}$ was carried out.

\section{Results and Discussion}

\subsection{Rotational Spectrum}

We recently studied the broadband rotational spectrum of the complex $\mathrm{F}_{5} \mathrm{PY}-\mathrm{CH}_{2} \mathrm{O}$ [35], generated in a supersonic jet driven by an expansion of $\mathrm{Ne}$. In the spectrum, the most intense lines were those of the monomers, followed by those of the complex $\mathrm{F}_{5} \mathrm{PY}_{-}-\mathrm{H}_{2} \mathrm{O}$. Several sets of rotational lines having a similar intensity to those of $\mathrm{F}_{5} \mathrm{PY}-\mathrm{CH}_{2} \mathrm{O}$ lines remained unassigned (see Figure S1 [35]). Those lines show the quadrupole coupling hyperfine structure (hfs) of a species carrying a ${ }^{14} \mathrm{~N}$ nucleus (see Figure 1 ). This hfs results from the interaction of the nuclear quadrupole moment of the ${ }^{14} \mathrm{~N}$ nucleus $(I=1), e Q$, with the electric field gradient, $q$, at the site of the $\mathrm{N}$ nucleus. The corresponding spectroscopic constants, $\chi_{\alpha \beta}(\alpha, \beta=a, b, c)$, are the elements of the nuclear quadrupole coupling tensor, set up in the inertial principal axis system representation, and are a direct measure of the electric field gradient at the nitrogen nucleus $\left(\chi_{\alpha \beta}=e Q q_{\alpha \beta}\right)$. FTMW spectroscopy has enough resolution to detect and resolve the individual quadrupole hyperfine components (see Figure 1). Once the lines of all known species were dropped from the spectrum, a 
search of possible species was conducted to identify the unknown spectra. Among the possible species, those corresponding to complexes of the molecules in the mixture with the carrier gas should be considered; in this case, the complex $\mathrm{F}_{5} \mathrm{PY}-\mathrm{Ne}$. Using the calculated rotational parameters for this complex, a prediction of the spectrum in the 2-8 GHz region was made. According to the predictions, this van der Waals complex has only the $\mu_{\mathrm{b}}$ type spectrum. The results of the theoretical calculations were valuable in the identification of rotational lines based on the frequency patterns and quadrupole coupling hyperfine structure. The quadrupole coupling constants are related to the electronic environment of this nucleus, and in this case, strongly depend on the orientation of the nitrogen atom in the principal inertial axis system. Figure 1 shows the comparison of the predicted spectrum for $\mathrm{F}_{5} \mathrm{PY}-\mathrm{Ne}$ (upper blue trace), with the observed one (black lower trace) in the 5.0-5.6 GHz range. In this figure, it is illustrated how the R-branch transitions $\mathrm{J}+1_{0, \mathrm{~J}+1} \leftarrow \mathrm{J}_{1, \mathrm{~J}}$ and $\mathrm{J}+$ $1_{1, \mathrm{~J}+1} \leftarrow \mathrm{J}_{0, \mathrm{~J}}$ or $\mathrm{J}+1_{\mathrm{J}+1,1} \leftarrow \mathrm{J}_{\mathrm{J}, 0}$ and $\mathrm{J}+1_{\mathrm{J}+1,0} \leftarrow \mathrm{J}_{\mathrm{J}, 1}$ formed well-defined doublets which were identified from frequency and intensity patterns for the parent species, and for the ${ }^{22} \mathrm{Ne}$ isotopologue with a natural abundance ratio ${ }^{22} \mathrm{Ne} /{ }^{20} \mathrm{Ne}=1 / 3$. In the excerpt, it can be seen how the comparison of the predicted and observed quadrupole coupling hyperfine structure patterns confirms the assignment.

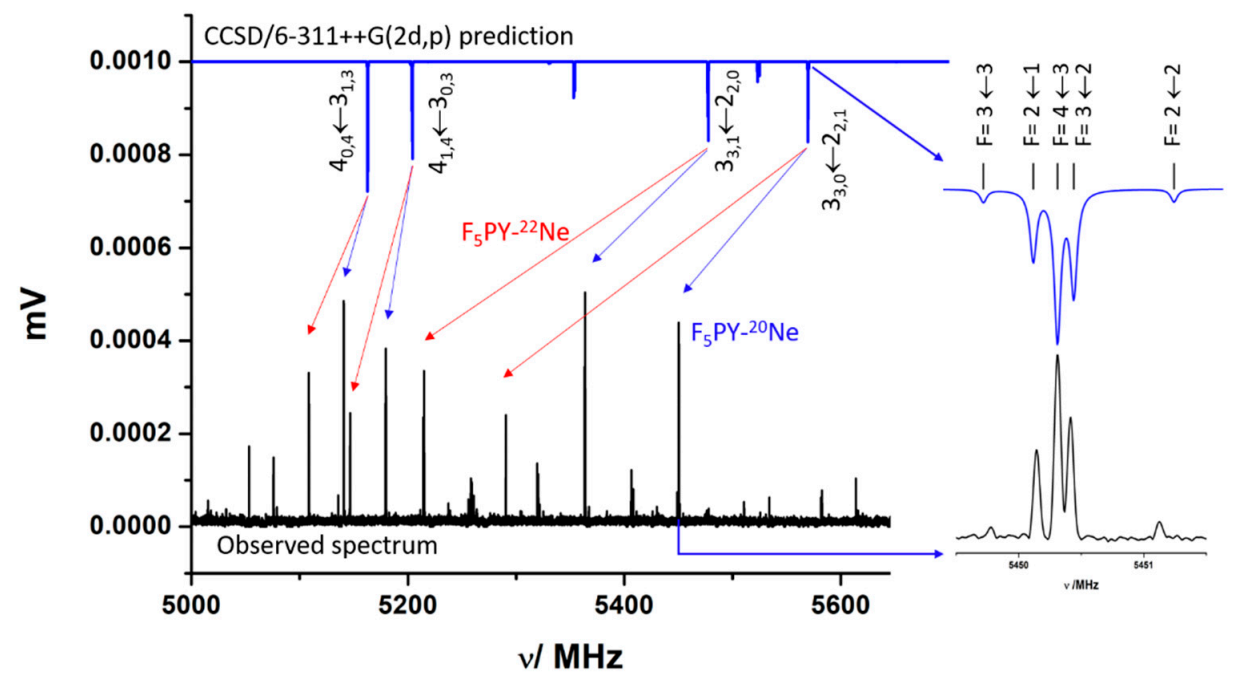

Figure 1. A section of the CP-FTMW spectrum in the 5.0-5.6 GHz region recorded from a supersonic jet expansion of $\mathrm{F}_{5} \mathrm{PY}$ diluted in Ne. The comparison with the prediction of the spectrum carried out from the rotational parameters predicted at CCSD/6-311++G(2d,p) (upper blue inverted trace) for $\mathrm{F}_{5}$ PY-Ne complex helps to identify the patterns of the $4_{0,4} \leftarrow 3_{1,3}, 4_{1,4} \leftarrow 3_{0,3}$ and $3_{3,1} \leftarrow 2_{2,0}, 3_{3,0} \leftarrow 2_{2,1}$ doublets for both the parent (blue arrow) and ${ }^{22} \mathrm{Ne}$ (red arrow) isotopologues. The excerpt compares the observed and predicted ${ }^{14} \mathrm{~N}$ quadrupole coupling hyperfine structure for the $3_{3,0} \leftarrow 22,1$ transition where the components are identified by the quantum number $F$, taking values from $(J+I)$ to $(J-I)$ reflecting the coupling between the overall rotation moment $(J)$ and ${ }^{14} \mathrm{~N}$ nuclear spin moments $(I=1)$.

The assignments of the complete $\mu_{\mathrm{b}}$-type spectra were followed from successive fittingprediction-measurement cycles. The analysis of the spectrum was conducted [43] using a Hamiltonian $\mathrm{H}=\mathrm{H}_{\mathrm{R}}{ }^{(\mathrm{A})}+\mathrm{H}_{\mathrm{Q}}$, where $\mathrm{H}_{\mathrm{R}}{ }^{(\mathrm{A})}$ represents Watson's A-reduced semirigid rotor Hamiltonian in the $\mathrm{I}^{\mathrm{r}}$ representation [44] and $\mathrm{H}_{\mathrm{Q}}$ is the nuclear quadrupole coupling interaction term [45]. The determinable spectroscopic parameters are the rotational constants, the centrifugal distortion constants, and the elements of the nuclear quadrupole coupling tensor $\chi$. Usually, for ${ }^{14} \mathrm{~N}$ only the diagonal elements of the tensor are determined. The experimental constants determined for the $\mathrm{F}_{5} \mathrm{PY}-{ }^{20} \mathrm{Ne}$ and $\mathrm{F}_{5} \mathrm{PY}^{22} \mathrm{Ne}$ isotopologues of the complex are collected in Table 1 , where they are compared to those calculated at the CCSC /6-311++G(2d,p) level. The parameters calculated at other levels are listed in Table S1. The observed frequencies are collected in Tables S9 and S10. 
Table 1. Experimental rotational parameters for the $\mathrm{F}_{5} \mathrm{PY}_{-}{ }^{20} \mathrm{Ne}$ and $\mathrm{F}_{5} \mathrm{PY}{ }^{22} \mathrm{Ne}$ isotopologues and their comparison to the predicted CCSD $/ 6-311++G(2 d, p)$ values for the parent species (Figure 2).

\begin{tabular}{|c|c|c|c|}
\hline \multirow[b]{2}{*}{ Param. ${ }^{a}$} & \multicolumn{2}{|c|}{ F5PY- ${ }^{20} \mathrm{Ne}$} & \multirow{2}{*}{$\frac{\text { F5PY-22 }}{{ }^{20}}$} \\
\hline & $\exp$ & CCSD & \\
\hline$A / \mathrm{MHz}$ & $940.26871(21)^{b}$ & 962.2 & $911.57618(20)$ \\
\hline$B / \mathrm{MHz}$ & 769.84484(19) & 780.8 & $752.84325(17)$ \\
\hline $\mathrm{C} / \mathrm{MHz}$ & $617.16139(13)$ & 618.2 & $615.66886(11)$ \\
\hline$\kappa$ & -0.05 & -0.05 & -0.07 \\
\hline$P_{\mathrm{aa}} / \mathrm{u} \AA^{2}$ & $468.93082(23)$ & 469.7 & $468.87713(21)$ \\
\hline$P_{\mathrm{bb}} / \mathrm{u} \AA^{2}$ & $349.94576(23)$ & 347.7 & $351.98461(21)$ \\
\hline$P_{\mathrm{cc}} / \mathrm{u} \AA^{2}$ & $187.53784(23)$ & 177.5 & $202.41668(21)$ \\
\hline$\Delta_{\mathrm{J}} / \mathrm{kHz}$ & $0.4055(25)$ & & $0.4890(23)$ \\
\hline$\Delta_{\mathrm{JK}} / \mathrm{kHz}$ & 6.329(10) & & $6.1360(91)$ \\
\hline$\Delta_{\mathrm{K}} / \mathrm{kHz}$ & $-5.5700(68)$ & & $-5.4288(59)$ \\
\hline$\delta_{\mathrm{J}} / \mathrm{kHz}$ & $0.1045(12)$ & & $0.1066(11)$ \\
\hline$\delta_{\mathrm{K}} / \mathrm{kHz}$ & $-4.2430(84)$ & & $-3.9140(73)$ \\
\hline $3 / 2\left(\chi_{\mathrm{aa}}\right) / \mathrm{MHz}$ & $2.9536(29)$ & 3.11 & $2.9595(26)$ \\
\hline $1 / 4\left(\chi_{\mathrm{bb}}-\chi_{\mathrm{cc}}\right) / \mathrm{MHz}$ & $-1.37697(75)$ & -1.51 & $-1.33170(67)$ \\
\hline$\chi_{\mathrm{aa}} / \mathrm{MHz}$ & 1.9687(19) & 2.07 & $1.9730(17)$ \\
\hline$\chi_{\mathrm{bb}} / \mathrm{MHz}$ & $-3.7383(25)$ & -4.05 & $-3.6499(22)$ \\
\hline$\chi_{\mathrm{cc}} / \mathrm{MHz}$ & $1.7696(25)$ & 1.98 & $1.6769(22)$ \\
\hline$n$ & 139 & & 118 \\
\hline$\sigma / \mathrm{kHz}$ & 3.2 & & 2.6 \\
\hline
\end{tabular}

${ }^{a} A, B$, and $C$ are the rotational constants. $\kappa$ is the Ray asymmetry parameter $\kappa=(2 B-A-C) /(A-C) . P_{\alpha \alpha}$ $(\alpha=\mathrm{a}, \mathrm{b}, \mathrm{c})$ are the planar moments of inertia, derived from the inertial moments $P_{\mathrm{cc}}=\left(I_{\mathrm{a}}+I_{\mathrm{b}}-I_{\mathrm{c}}\right) / 2 . \Delta_{\mathrm{J}}, \Delta_{\mathrm{JK}}$ $\Delta_{\mathrm{K}}, \delta_{\mathrm{J}}$, and $\delta_{\mathrm{K}}$, are the quartic centrifugal distortion constants. $\chi_{\mathrm{aa}}, \chi_{\mathrm{bb}}$, and $\chi_{\mathrm{cc}}$ are the ${ }^{14} \mathrm{~N}$ quadrupole coupling constants. $n$ is the number of quadrupole coupling components fitted. $\sigma$ is the rms deviation of the fit. ${ }^{\mathrm{b}}$ Standard errors in parentheses in units of the last digit.

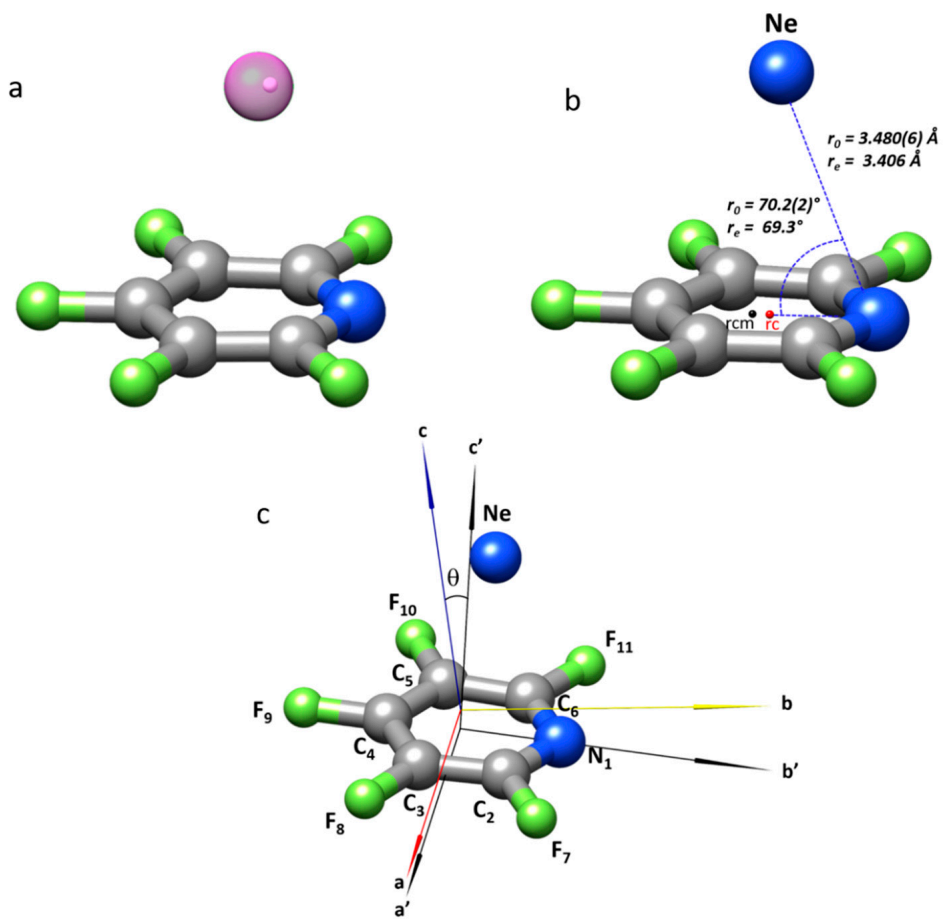

Figure 2. The structure of $F_{5} P Y-N e$ adduct: (a) The CCSD/6-311++G $(2 d, p)$ predicted structure is drawn with a translucent $\mathrm{Ne}$ atom to show the location of the Ne atom (white small sphere) according to the $r_{\mathrm{s}}$ coordinates. (b) The structure gives the values of the $r_{0}$ and $r_{\mathrm{e}}$ (MP2/aug-cc-pVTZ) van der Waals bonding parameters. (c) The location of the $\mathrm{F}_{5} \mathrm{PY}$ and $\mathrm{F}_{5} \mathrm{PY}-\mathrm{Ne}$ inertial axes is shown together with the definition of the angle $\theta$. $\mathrm{rcm}$ is the $\mathrm{F}_{5} \mathrm{PY}$ center of mass and $\mathrm{rc}$ is the ring centroid. 


\subsection{Structure of the Complex}

The comparison of the rotational constants, the corresponding inertial $I_{\alpha}$ and planar moments $P_{\alpha \alpha}(\alpha=a, b$, or $c)$, and the quadrupole coupling constants $\chi_{\alpha \alpha}$ of $\mathrm{F}_{5} \mathrm{PY}-\mathrm{Ne}$ with those of the monomer, $\mathrm{F}_{5} \mathrm{PY}$, provides experimental insights into the structure of the complex (see Table 2 and Figure 2). $\mathrm{F}_{5} \mathrm{PY}$ is a planar molecule with $C_{2 \mathrm{v}}$ symmetry. The $C_{2}$ axis is coincident with the inertial axis $b$ and the plane of the molecule is coincident with the $\sigma_{\mathrm{ab}}$ inertial plane, while the symmetry plane perpendicular to the molecule can be identified as the $\sigma_{\mathrm{bc}}$. In correspondence, the planar moment $P_{c c}=\left(I_{a}+I_{b}-I_{c}\right) / 2=\sum_{i} m_{i} c_{i}^{2}$, giving the mass extension out of the $a b$ inertial plane, is nearly zero for $\mathrm{F}_{5} \mathrm{PY}$ (see Table 2 and Figure 2, where the principal axes of $\mathrm{F}_{5} \mathrm{PY}$ are labeled with a prime). The changes in the rotational parameters upon complexation give interesting clues about the structure and symmetry of the $\mathrm{F}_{5} \mathrm{PY}-\mathrm{Ne}$ adduct. $P_{\mathrm{cc}}$ is rather large for the cluster (see Table 2), indicating that Ne lies above (or below) the $\mathrm{F}_{5} \mathrm{PY}$ ring plane. The planar moment $P_{\text {aa }}$, giving the mass extension out of the $b c$ plane, is nearly the same for the monomer and the cluster (see Table 2). This proves that the Ne lies in the $\sigma_{\mathrm{bc}}$ molecular plane, which is preserved as a symmetry plane upon formation of the complex, thus giving a $C_{\mathrm{s}}$ symmetry of $\mathrm{F}_{5} \mathrm{PY}$ Ne. Furthermore, the rotational constant $C$ changes just about $1 \%$ indicating that the $\mathrm{Ne}$ atom lies close to the $c$ inertial axis. It is worth noting that the $P_{\text {aa }}$ values show a slight decrease when going from $\mathrm{F}_{5} \mathrm{PY}$ to $\mathrm{F}_{5} \mathrm{PY}-{ }^{20} \mathrm{Ne}$ or $\mathrm{F}_{5} \mathrm{PY}-{ }^{22} \mathrm{Ne}$, revealing the contribution of large-amplitude intermolecular vibrations in the complex to this planar moment.

Table 2. Comparison of the rotational constants $(A, B, C)$, the moments of inertia $\left(I_{\mathrm{a}}, I_{\mathrm{b}}, I_{\mathrm{c}}\right)$, and the planar moments $\left(P_{\mathrm{aa}}, P_{\mathrm{bb}}, P_{\mathrm{cc}}\right)$ of $\mathrm{F}_{5} \mathrm{PY}$ and $\mathrm{F}_{5} \mathrm{PY}-\mathrm{Ne}$.

\begin{tabular}{cccc}
\hline Parameters & $\mathbf{F}_{5} \mathbf{P Y}$ & $\mathbf{F}_{5} \mathbf{P Y} \mathbf{-}^{\mathbf{2 0}} \mathbf{N e}$ & $\mathbf{F}_{5} \mathbf{P Y}{ }^{22} \mathbf{N e}$ \\
\hline$A / \mathrm{MHz}$ & $1481.58184(19) \mathrm{b}$ & $940.26871(21)$ & $911.57618(20)$ \\
$B / \mathrm{MHz}$ & $1075.37335(17)$ & $769.84484(19)$ & $752.84325(17)$ \\
$\mathrm{C} / \mathrm{MHz}$ & $623.11194(16)$ & $617.16139(13)$ & $615.66886(11)$ \\
& & & \\
$I_{\mathrm{a}} / \mathrm{u}^{2}$ & $341.107724(44)$ & $537.80275(12)$ & $554.73049(12)$ \\
$I_{\mathrm{b}} / \AA^{2}$ & $469.956791(74)$ & $656.85847(16)$ & $671.69241(15)$ \\
$I_{\mathrm{c}} / \mathrm{u}^{2}$ & $811.05653(21)$ & $819.36283(17)$ & $821.34916(15)$ \\
& & & \\
$P_{\mathrm{aa}} / \mathrm{u} \AA^{2}$ & $469.95280(16)$ & $468.93082(23)$ & $468.87713(21)$ \\
$P_{\mathrm{bb}} / \mathrm{u} \AA^{2}$ & $341.10373(16)$ & $349.94576(23)$ & $351.98461(21)$ \\
$P_{\mathrm{cc}} / \mathrm{u} \AA^{2}$ & $0.00399(16)$ & $187.53784(23)$ & $202.41668(21)$ \\
& & & \\
$\chi_{\mathrm{aa}} / \mathrm{MHz}$ & $1.9664(53)$ & $1.9687(19)$ & $1.9730(17)$ \\
$\chi_{\mathrm{bb}} / \mathrm{MHz}$ & $-3.9534(72)$ & $-3.7383(25)$ & $-3.6499(22)$ \\
$\chi_{\mathrm{cc}} / \mathrm{MHz}$ & $1.9870(72)$ & $1.7696(25)$ & $1.6769(22)$ \\
\hline
\end{tabular}

a Taken from reference [35]. ${ }^{\mathrm{b}}$ Standard errors in parenthesis in units of the last digit.

The $\chi_{\mathrm{aa}}, \chi_{\mathrm{bb}}$, and $\chi_{\mathrm{cc}}$ quadrupole coupling constants shown in Table 2 are the diagonal elements of the quadrupole coupling tensor set up in the principal inertial axis system. For $\mathrm{F}_{5} \mathrm{PY}$, due to the $C_{2 \mathrm{v}}$ symmetry, the principal quadrupole coupling axis and inertial axis systems are coincident (i.e., $a \rightarrow y, b \rightarrow z, c \rightarrow x$ ) [35,46], so the quadrupole coupling tensor is diagonal. The conservation of the $\sigma_{\mathrm{bc}}$ plane as a symmetry plane in the complex implies that the coincidence of the $a$ inertial and $y$ quadrupole coupling axes is also preserved in the complex. This can be deduced from the near equality of the $\chi_{\text {aa }}$ quadrupole coupling constant in $\mathrm{F}_{5} \mathrm{PY}$ and $\mathrm{F}_{5} \mathrm{PY}-\mathrm{Ne}$ (see Table 2). The orientation of the $b$ and $c$ inertial axes of the aggregate results from the rotation of the monomer axes by an angle $\theta_{\mathrm{bb}^{\prime}}$ as defined in Figure 2. Using a value of $\theta_{\mathrm{bb}^{\prime}}=11.0^{\circ}$ to transform the experimental quadrupole coupling tensor constants of the monomer into those expected for the adduct, it gives $\chi_{\mathrm{bb}}=-3.737 \mathrm{MHz}$ and $\chi_{\mathrm{cc}}=1.771 \mathrm{MHz}$, values, very close to the experimental values of $\mathrm{F}_{5} \mathrm{PY}{ }^{20} \mathrm{Ne}$ (see Table 2). An angle of $13.1^{\circ}$ gives $\chi_{\mathrm{bb}}=-3.648 \mathrm{MHz}$ and $\chi_{\mathrm{cc}}=1.682 \mathrm{MHz}$, 
close to the values of $\mathrm{F}_{5} \mathrm{PY}-{ }^{22} \mathrm{Ne}$. This evidences that the electric field gradient, and thus the electronic environment around the $\mathrm{N}$ atom, is not altered upon formation of the complex.

The degree of agreement between the experimental and calculated inertial data is better appreciated if we take the values of the planar moments of inertia $P_{\alpha \alpha}$. The three translational motions of the isolated $\mathrm{Ne}$ are replaced by three low-energy large-amplitude vibrational modes upon formation of the complex. Due to these van der Waals motions, which may add vibration-rotation interaction contributions to the moments of inertia, the usual methods for structure determination may supply poor results. One of these vibrations is a stretching $v_{\mathrm{s}}$, and the other two, $v_{\mathrm{ra}}$ and $v_{\mathrm{rb}}$, can be associated to rotations of $\mathrm{Ne}$ around $\mathrm{F}_{5} \mathrm{PY}$. For small displacements around the equilibrium structure these are described as nearly degenerate displacements of Ne in trajectories parallel to $a\left(v_{\mathrm{ra}}\right)$ and $b$ $\left(v_{\mathrm{rb}}\right)$ axes. The frequencies calculated at B3LYP-D3BJ $/ 6-311++\mathrm{G}(2 \mathrm{~d}, \mathrm{p})$ are $v_{\mathrm{s}}=53.1 \mathrm{~cm}^{-1}$, $v_{\mathrm{ra}}=22.2 \mathrm{~cm}^{-1}$, and $v_{\mathrm{rb}}=24.6 \mathrm{~cm}^{-1}$. The frequencies calculated with the MP2 method and the same basis set are $v_{\mathrm{s}}=48.1 \mathrm{~cm}^{-1}, v_{\mathrm{ra}}=18.4 \mathrm{~cm}^{-1}$ and $v_{\mathrm{rb}}=18.5 \mathrm{~cm}^{-1}$. It can be seen in Table 1, Table 2, and Table S1 that the planar moments $P_{\mathrm{aa}}$ and $P_{\mathrm{bb}}$ are well-described theoretically in correspondence with the good description of $\mathrm{F}_{5} \mathrm{PY}$ rotational parameters at the levels of calculation used (see Table S2) [35]. The main discrepancies come from the planar moment $P_{\mathrm{cc}}$, which is highly dependent on the position of the Ne atom relative to the ring. In this case, the best description is made at the CCSD level. Part of these discrepancies may arise from the intermolecular vibrational contributions, in particular stretching vibrations, which may result in larger $P_{\mathrm{cc}}$ experimental values corresponding with average ground vibrational state Ne-ring distances larger than those corresponding to equilibrium. As observed previously [35], the best agreement for the quadrupole coupling constants is obtained at MP2/6-311++G(2d,p) level.

The structure of $\mathrm{F}_{5} \mathrm{PY}-\mathrm{Ne}$ has been further investigated from the analysis of the rotational parameters of the two observed isotopologues, by using the substitution $\left(r_{\mathrm{S}}[47,48]\right)$, effective $\left(r_{0}[49]\right)$, and mass dependence $\left(r_{\mathrm{m}}[49,50]\right)$ methods, as illustrated in Figure 2 . The substitution, $r_{\mathrm{s}}$, method compares the inertial moments of the parent and monosubstituted isotopologues through the Kraitchman equations [47] to give the absolute values of the substituted atom coordinates-in this case, $\mathrm{Ne}$-in the principal inertial axis system of the parent molecule. The signs of the coordinates can be assigned from any reasonable geometry as effective $\left(r_{0}\right)$ or theoretical $\left(r_{\mathrm{e}}\right)$ structures. This experimental approach has some limitations in locating atoms close to the principal inertial axes, or for light atoms such as hydrogen. The $r_{\mathrm{s}}$ coordinates of Ne in the complex are given in Table 3 , where these are compared with those from the $r_{0}$ method and theoretical CCSD calculations.

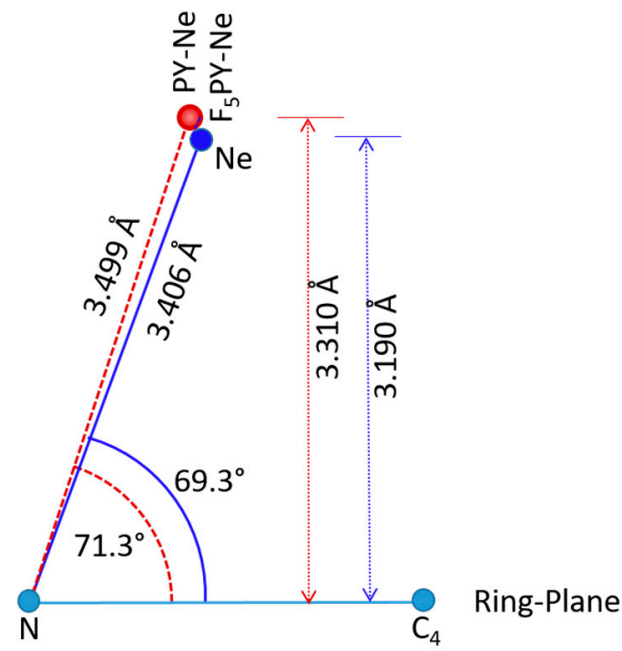

Figure 3. A sketch where the CCSD/6-311++G(2d,p) van der Waals predicted structure of $\mathrm{F}_{5} \mathrm{PY}-\mathrm{Ne}$ (blue) is compared with that of PY-Ne (red) [20]. 
Table 3. Principal inertial axis coordinates for the neon atom of pentafluoropyridine $\cdots$ Ne complex. The table compares the substitution $\left(r_{\mathrm{s}}\right)$ and effective $\left(r_{0}\right)$ coordinates with those $\left(r_{\mathrm{e}}\right)$ calculated at the CCSD /6-311++G(2d,p) (CCSD) computational methods. The table also compares the effective bonding parameters determined from a least-squares fit of the observed rotational constants, and the angle $\theta$ of rotation between the principal inertial axis systems of $\mathrm{F}_{5} \mathrm{PY}$ and $\mathrm{F}_{5} \mathrm{PY}-\mathrm{Ne}$.

\begin{tabular}{|c|c|c|c|}
\hline $\mathbf{r}_{\mathrm{s}}$ Coordinates & $a$ & $b$ & $c$ \\
\hline$\left|r_{s}\right|$ & {$[0.0000]^{\mathrm{a}}$} & $0.9672(15)^{b}$ & $2.75959(54)$ \\
\hline $\mathbf{r}_{0}$ & 0.0000 & $0.911(23)$ & $2.8134(64)$ \\
\hline $\mathrm{r}_{\mathrm{e}}^{\mathrm{CCSD}}$ & 0.0000 & 0.814 & 2.757022 \\
\hline Parameters & $r_{0}$ & $r_{\mathrm{e}}^{\mathrm{CCSD}}$ & $r_{\mathrm{s}}$ \\
\hline$r(\mathrm{~N} \cdots \mathrm{Ne}) / \AA$ & $3.480(6)$ & 3.359 & \\
\hline$\angle(\mathrm{CNNe}) /^{\circ}$ & $70.2(2)$ & 69.2 & \\
\hline$r(\mathrm{rc} \cdots \mathrm{Ne}) \mathrm{c} / \AA$ & $3.278(8)$ & 3.192 & \\
\hline $\mathrm{R}=r(\mathrm{rcm} \cdots \mathrm{Ne})^{\mathrm{d} / \AA}$ & $3.307(9)$ & 3.215 & 3.260 \\
\hline$\angle(\mathrm{Ne} \cdots \mathrm{rc} \cdots \mathrm{N}) /^{\circ}$ & $86.8(5)$ & 86.8 & \\
\hline$\angle(\mathrm{Ne} \cdots \mathrm{rcm} \cdots \mathrm{N}) /^{\circ}$ & $82.8(5)$ & 82.2 & \\
\hline$\varphi^{\mathrm{e} / \circ}$ & $7.2(5)$ & 7.2 & 8.1 \\
\hline$\theta^{\mathrm{f} / o}$ & 9.8 & 8.6 & \\
\hline Fit & experimental & Residuals $\mathrm{g}$ & \\
\hline $\mathrm{A} / \mathbf{M H z}$ & $940.26871(21)$ & -1.56 & \\
\hline $\mathrm{B} / \mathrm{MHz}$ & 769.84484(19) & 0.41 & \\
\hline $\mathrm{C} / \mathrm{MHz}$ & $617.16139(13)$ & 0.60 & \\
\hline $\mathrm{A} / \mathrm{MHz}$ & $911.57618(20)$ & -0.84 & \\
\hline $\mathrm{B} / \mathrm{MHz}$ & 752.84325(17) & 1.13 & \\
\hline $\mathrm{C} / \mathrm{MHz}$ & $615.66886(11)$ & 0.47 & \\
\hline
\end{tabular}

${ }^{a}$ The coordinate in square brackets is fixed to zero due to symmetry. ${ }^{b}$ Estimated errors are given in parentheses in units of the last digit calculated according to ref [48]. ${ }^{c}$ Distance from Ne to the ring-centroid (rc, see Figure 3).

${ }^{d}$ Distance from Ne to the $F_{5}$ PY center of mass (rcm, see Figure 3). ${ }^{e}$ angle between the line from Ne to the ring center of mass $(\mathrm{rcm})$ and a line perpendicular to the ring. ${ }^{\mathrm{f}}$ see Figure 2 for definition. ${ }^{\mathrm{g}}$ Differences between the experimental constants and those calculated from the determined $r_{0}$ structure.

A total or partial effective $r_{0}$ structure can be obtained when bond distances and angles are obtained from a least-squares fit of the inertial moments of all observed isotopologues. For $\mathrm{F}_{5} \mathrm{PY}-\mathrm{Ne}$, we have assumed that the structure of $\mathrm{F}_{5} \mathrm{PY}$ does not change upon complexation, so the previously determined $r_{0}$ structure [35] was kept fixed to determine the $r(\mathrm{~N}-\mathrm{Ne})$ distance and $\angle \mathrm{C}_{4}-\mathrm{N}-\mathrm{Ne}$ angle. The results are given in Table 3 and summarized in Figure 2, where it can be seen that the $r_{0}$ value of the angle $\theta$ is in good agreement with that calculated from the quadrupole coupling parameters, if we take into account that these may be affected by the effects of intermolecular vibrations. The comparison of the experimental structures with those derived theoretically at the CCSD/6-311++G(2d,p) level shown in Table 3, or with other methods (see Table S3) reflect the same degree of agreement pointed out when comparing the experimental values of the planar moments (see above); the main discrepancies come from the distance between the Ne atom and the ring plane. The CCSD method gives the closest results and nicely reproduces the $r_{\mathrm{s}}$ values for $\mathrm{F}_{5} \mathrm{PY}-\mathrm{Ne}$. The CCSD predictions could then be considered reasonable, taking into account that the experimental $r_{0}$ data might be more affected by intermolecular vibration contributions, giving rise to larger distances.

\subsection{Comparison with Related Complexes}

The experimental and CCSD geometry of $\mathrm{F}_{5} \mathrm{PY}-\mathrm{Ne}$ is compared in Table 4 with those of the three related complexes, PY-Ne, $\mathrm{F}_{6} \mathrm{BZ}-\mathrm{Ne}$, and BZ-Ne. The geometrical parameters given are the distance $\mathrm{R}$ from $\mathrm{Ne}$ to the ring center of mass, and the angle $\varphi$ between the line from $\mathrm{Ne}$ to the ring center of mass and a line perpendicular to the ring plane (Figure 3). These parameters allow a direct comparison with the geometries of two of these complexes, 
PY-Ne and BZ-Ne, already described experimentally. In all cases, the computational results reproduce well the $r_{\mathrm{s}}$ values for $\mathrm{F}_{5} \mathrm{PY}-\mathrm{Ne}$ and the equilibrium $r_{\mathrm{e}}$ values derived from fitting the rotational parameters to Lennard-Jones type potential energy functions for the intramolecular stretching motions for PY-Ne [17] and BZ-Ne [13]. In the case of the $r_{0}$ values, the experimental distances are always larger than the predicted equilibrium distances, and this fact may reflect the contribution of large-amplitude intermolecular vibrations, especially the stretching vibrations to the ground vibrational state parameters. The longest predicted intermolecular $\mathrm{R}$ distances are obtained for the complexes of the hydrogenated aromatic rings (PY-Ne and BZ-Ne). The perfluorination of the aromatic systems decreases the intermolecular distance around $0.1 \AA$. The changes in the structures of PY-Ne and $\mathrm{F}_{5} \mathrm{PY}-\mathrm{Ne}$ are sketched in Figure 3. In both, the RG atom is shifted towards the $\mathrm{N}$ atom, but in $\mathrm{F}_{5} \mathrm{PY}-\mathrm{Ne}$ it is closer to the ring plane.

Table 4. Intermolecular distance between the center of mass of the aromatic system and the Neon atom $(\AA), R$, and the deviation of the perpendicular axes $\left(^{\circ}\right), \varphi$. The values from experimental data sources are provided in parenthesis.

\begin{tabular}{cccccc}
\hline Param. & Method & F $_{5}$ PY-Ne & PY-Ne & F $_{6}$ BZ-Ne & BZ-Ne \\
\hline $\mathrm{R} / \AA$ & CCSD & 3.215 & 3.325 & 3.199 & 3.313 \\
& $\left(r_{\mathrm{s} / \mathrm{e}}, r_{0}\right)$ & $\left(3.260^{\mathrm{a}}, 3.302\right)$ & $\left(3.316^{\mathrm{b}}, 3.400^{\mathrm{c}}\right)$ & & $\left(3.2989^{\mathrm{d}}, 3.462^{\mathrm{e}}\right)$ \\
\hline$\varphi /^{\circ}$ & $\begin{array}{c}\mathrm{CCSD} \\
\left(r_{\mathrm{s} / \mathrm{e}}, r_{0}\right)\end{array}$ & $\begin{array}{c}7.8 \\
\left(7.2^{\mathrm{a}}, 8.1\right)\end{array}$ & $\begin{array}{c}4.6 \\
\left(4.2^{\mathrm{b}}, 6.2^{\mathrm{c}}\right)\end{array}$ & 0.0 & 0.0 \\
& & & $\left(0.0^{\mathrm{d}}, 0.0^{\mathrm{e}}\right)$ \\
\hline
\end{tabular}

${ }^{\mathrm{a}} r_{\mathrm{S}}$ value, this work. ${ }^{\mathrm{b}}$ Equilibrium values corresponding to a study of van der Waals motions [17]. ${ }^{\mathrm{c}}$ Ref. [20]

${ }^{d}$ Equilibrium values corresponding to a study of van der Waals motions Ref. [13]. ${ }^{e}$ Ref. [13].

\subsection{Binding Energies}

The calculated binding energies at the $\operatorname{CCSD}(\mathrm{T})$ computational level and the DFT-SAPT contributions have been gathered in Table 5 . As in the case of the intermolecular distances, the binding energies for the neon complexes of the hydrogenated aromatic systems are smaller than the perfluorinated ones by approx. $2 \mathrm{~kJ} \mathrm{~mol}^{-1}$. The DFT-SAPT partition shows that in all cases, dispersion is the most important contribution, with values between -3.1 and $-3.9 \mathrm{~kJ} \mathrm{~mol}^{-1}$. The values of the dispersion term increase with the molecular weight of the aromatic system. A comparison of these values with those obtained with the empirical D3(BJ) method provides an excellent linear correlation $\left(R^{2}=0.99\right.$, see Figure S2). The second most important term is the repulsive exchange that also increases with the molecular weight of the aromatic system from $2.2 \mathrm{~kJ} \mathrm{~mol}^{-1}$ in PY-Ne to $3.3 \mathrm{~kJ} \mathrm{~mol}^{-1}$ in $\mathrm{Bz}-\mathrm{Ne}$. The other three attractive terms have small contributions with the following trend in absolute value in each complex: electrostatic $>\delta \mathrm{HF}>$ Induction.

Table 5. Bonding energies (BE in $\mathrm{kJmol}^{-1}$ ) calculated at the $\mathrm{CCSD}(\mathrm{T})$ level and DFT-SAPT contributions for the complexes PY-Ne, BZ-Ne, $\mathrm{F}_{5} \mathrm{PY}-\mathrm{Ne}$, and $\mathrm{F}_{6} \mathrm{BZ}-\mathrm{Ne}$.

\begin{tabular}{|c|c|c|c|c|c|c|}
\hline & $\mathrm{BE}[\mathrm{CCSD}(\mathrm{T})]$ & Elect. & Exchange & Induction & Dispersion & $\delta \mathrm{HF}$ \\
\hline PY-Ne & -2.9 & -0.66 & 2.21 & 0.02 & -3.05 & -0.10 \\
\hline BZ-Ne & -2.8 & -0.81 & 2.67 & 0.01 & -3.27 & -0.14 \\
\hline $\mathrm{F}_{5} \mathrm{PY}-\mathrm{Ne}$ & -4.9 & -0.87 & 2.91 & -0.04 & -3.74 & -0.13 \\
\hline $\mathrm{F}_{6} \mathrm{BZ}-\mathrm{Ne}$ & -4.9 & -1.03 & 3.33 & 0.01 & -3.87 & -0.16 \\
\hline
\end{tabular}

The electron density analysis of the complexes shows the presence of three intermolecular BCPs in the $\mathrm{F}_{5} \mathrm{PY}-\mathrm{Ne}$ complex (see Figure 4), one in the PY-Ne and six in the BZ-Ne and $\mathrm{F}_{6} \mathrm{BZ}-\mathrm{Ne}$ ones (see the molecular graphs in Tables S5-S8). The values of the electron density of all the intermolecular BCPs are very close to what is considered to be the van der Waals limit in QTAIM theory (0.002 au). The largest value is obtained in the $\mathrm{F}_{6} \mathrm{BZ}-\mathrm{Ne}$ complex $(0.0027 \mathrm{au})$ and the smallest is obtained in the PY-Ne one $(0.0022 \mathrm{au})$. Thus, the electron density values also are in concordance of very weak interactions between the two 
molecules. The NCIPlot analysis shows a region of weak interaction between the neon atom and the aromatic system (see Figure 4 for the $\mathrm{F}_{5} \mathrm{PY}-\mathrm{Ne}$ complex).
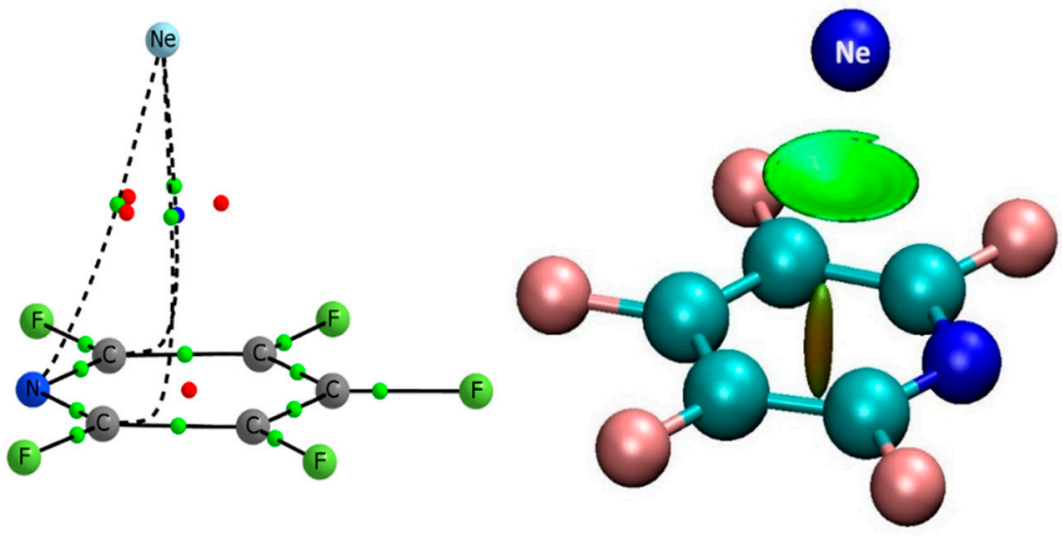

\begin{tabular}{lll}
\hline Strong & Van der Waals & Strong \\
attraction & Weak attraction & repulsion
\end{tabular}

Figure 4. Molecular graph showing three bond critical points (left) and NCIPlot (right) of the $\mathrm{F}_{5} \mathrm{PY}-\mathrm{Ne}$ complex.

\section{Materials and Methods}

\subsection{Theoretical Methods}

Starting values of the rotational parameters were obtained from optimization of the $\mathrm{F}_{5} \mathrm{PY}-\mathrm{Ne}$ complex geometries using B3LYP-D3BJ/6-311++G(2d,p) [51-53], MP2/6$311++\mathrm{G}(2 \mathrm{~d}, \mathrm{p})[54,55]$, usually giving good predictions of the ${ }^{14} \mathrm{~N}$ quadrupole coupling constants [56], and MP2/aug-cc-pVTZ levels [57]. The results are collected in Table S1 of the supporting information. Finally, the geometry of the isolated molecules and complexes was optimized at the CCSD/6-311++G(2d,p) computational level. In order to improve the energetic description, a single point calculation at $\operatorname{CCSD}(\mathrm{T}) / 6-311++\mathrm{G}(2 \mathrm{~d}, \mathrm{p})$ [58] was performed using the previously obtained geometries. These calculations were carried out with the Gaussian-16 program [59]. The binding energy of the complexes was analyzed with the DFT-SAPT [60,61] method in the Molpro program [62], using the PBE0 functional [63] and the aug-cc-pVTZ basis set. The electronic characteristics of the complexes were analyzed with the quantum theory of atoms in molecules (QTAIM) [64] and the NCIPlot [65] using the CCSD/6-311++G(2d,p) wavefunction.

\subsection{Experimental Methods}

A commercial sample of $\mathrm{F}_{5} \mathrm{PY}$ was used. The spectrum of the $\mathrm{F}_{5} \mathrm{PY}-\mathrm{Ne}$ complex was created in a supersonic jet of $\mathrm{Ne}$ and investigated using a chirped-pulse Fourier transform microwave spectrometer (CP-FTMW) [66], described elsewhere [67], and a narrowband Fabry-Perot Fourier transform microwave spectrometer (FP-FTMW) [68,69]. F5 PY was kept at room temperature in a deposit inserted in the gas line close to the solenoid valve in both spectrometers. In the CP-FTMW instrument, which covers the 2-8 GHz frequency range, the spectra were recorded in steps of $2 \mathrm{GHz}$. The carrier gas was $\mathrm{Ne}$ at backing pressures of about 2 bar, expanding through a $0.8 \mathrm{~mm}$ nozzle in pulses of $700 \mu$ s duration. Chirp pulses of $4 \mu$ s were created by an arbitrary waveform generator and amplified to $20 \mathrm{~W}$. The polarization signal was radiated from a horn antenna in a direction perpendicular to that of the expanding gas. A molecular transient emission spanning $40 \mu \mathrm{s}$ was then detected through a second horn, recorded with a digital oscilloscope, and Fourier-transformed to the frequency domain. The accuracy of frequency measurements was higher than $10 \mathrm{kHz}$. In the FP-FTMW instrument, operated in the 5-13 GHz frequency range, Ne was also used at stagnation pressures ranging up to 2 bar, expanding in pulses of about $800 \mu$ s through a $0.8 \mathrm{~mm}$ nozzle. Short (typ. $0.3 \mu \mathrm{s}, 10-300 \mathrm{~mW}$ ) microwave pulses were used for polarization 
purposes. Typically, a ca. $400 \mu$ s-length time-domain spectrum was recorded at 40-100 ns intervals and converted to the frequency domain by a fast Fourier transformation. Due to the collinear arrangement of the jet and resonator axis, each rotational transition split into two Doppler components, so the resonant frequencies were taken as the arithmetic mean of both components. Frequency accuracy was lower than $3 \mathrm{kHz}$. The rotational spectra of the ${ }^{22} \mathrm{Ne}$ isotopologue was observed in its natural abundance.

\section{Conclusions}

In this work, we studied the rotational spectrum of the complex $\mathrm{F}_{5} \mathrm{PY}-\mathrm{Ne}$ to characterize its structure and properties. These data, together with those from the rotational spectra of the complexes of BZ [12,13] and PY [17-20] with Ne, were used as a benchmark for the theoretical data obtained on these complexes using CCSD/6-311++G(2d,p) level with excellent results. The calculations were extended to the complex $\mathrm{F}_{6} \mathrm{BZ}-\mathrm{Ne}$ to investigate the effects of perfluorination of BZ and PY in the interaction of these compounds with Ne. The experimental and theoretical results show that the van der Waals distances are shorter by ca. $0.1 \AA$ in the perfluorinated compounds, indicating the latter are strongly bound. The binding energies calculated for the complexes corroborate this conclusion, since the energies of BZ-Ne and PY-Ne $\left(-2.9 \mathrm{kcal} \mathrm{mol}^{-1}\right)$ are smaller than the values $(-4.9 \mathrm{kcal}$ $\mathrm{mol}^{-1}$ ) of perfluorinated compounds.

Supplementary Materials: The following are available online, Complete reference [59]; Figure S1: Observed broadband FTMW spectrum $(2-8 \mathrm{GHz})$ of a mixture of $\mathrm{C}_{5} \mathrm{~F}_{5} \mathrm{~N}\left({ }^{*}\right)$ and $\mathrm{CH}_{2} \mathrm{CO}\left({ }^{\circ}\right)$ (reference [35]). Figure S2: Correlation between the dispersion component of the DFT-SAPT energy and the D3(BJ) correction; Table S1: Predicted Rotational parameters for the perfluoropyridine $\cdots$ Ne complex at different levels of theory; Table S2: Observed and predicted perfluoropyridine rotational parameters [34]; Table S3: Principal inertial axis $r_{\mathrm{S}}$ coordinates of the neon atom of pentafluoropyridine $\cdots \mathrm{Ne}$ complex; Table S4: $r_{0}$ geometry of pentafluoropyridine $\cdots$ Ne complex; Tables S5-S8: Molecular graphs, Optimized geometries, and energies at CCSD/6-311++G(2d,p) computational level for the complexes studied in this work; Tables S9 and S10: Observed rotational transitions and residuals of the parent and ${ }^{22} \mathrm{Ne}$ isotopologues.

Author Contributions: Conceptualization, S.B., I.A. and J.C.L.; methodology, A.M., S.B., I.A. and J.C.L.; software, I.A., J.C.L.; validation, A.M., S.B., I.A. and J.C.L.; formal analysis, A.M., S.B., I.A. and J.C.L.; investigation, A.M., S.B., I.A. and J.C.L.; data curation, A.M., S.B., I.A. and J.C.L.; writingoriginal draft preparation, J.C.L.; writing-review and editing, A.M., S.B., I.A. and J.C.L.; supervision, S.B., A.M. and I.A.; projects administration, S.B., I.A. and J.C.L.; funding acquisition, S.B., I.A. and J.C.L. All authors have read and agreed to the published version of the manuscript.

Funding: This research was funded by the Ministerio de Economía y Competitividad of Spain, Grant CTQ2016-75253-P, the Ministerio de Ciencia, Innovación y Universidades of Spain, Grant No. PGC2018-094644-B-C22 and Comunidad Autónoma de Madrid, Grant no. P2018/EMT-4329 AIRTEC-CM).

Data Availability Statement: Data supporting reported results can be found as supplementary material available online. Any other data concerning this research can be requested from the authors.

Conflicts of Interest: The authors declare no conflict of interest.

Sample Availability: Samples of the compounds are commercially available.

\section{References}

1. Grabow, J.-U.; Caminati, W. Microwave Spectroscopy: Experimental Techniques. Front. Mol. Spectrosc. 2009, 383-454. [CrossRef]

2. Pate, B.H. Taking the Pulse of Molecular Rotational Spectroscopy. Science 2011, 333, 947-948. [CrossRef]

3. Li, X.; Lu, T.; Obenchain, D.A.; Zhang, J.; Herbers, S.; Grabow, J.; Feng, G. The Characteristics of Disulfide-Centered Hydrogen Bonds. Angew. Chem. 2021, 133, 5902-5906. [CrossRef]

4. Xu, Y.; Zhang, J.; Li, W.; Li, J.; Feng, G. High-Resolution Rotational Spectroscopy and Interstellar Search for Isopropyl Isothiocyanate. ACS Earth Space Chem. 2021, 5, 33-39. [CrossRef]

5. Caminati, W.; Grabow, J.-U. Microwave Spectroscopy: Molecular Systems. In Frontiers of Molecular Spectroscopy; Laane, J., Ed.; Elsevier: Amsterdam, The Netherlands, 2009; pp. 455-552. [CrossRef] 
6. Blanco, S.; Macario, A.; García-Calvo, J.; Revilla-Cuesta, A.; Torroba, T.; López, J.C. Microwave Detection of Wet Triacetone Triperoxide (TATP): Non-Covalent Forces and Water Dynamics. Chem. Eur. J. 2021, 27, 1680-1687. [CrossRef] [PubMed]

7. Puzzarini, C. Computational Approach to Rotational Spectroscopy. In Computational Strategies for Spectroscopy; John Wiley \& Sons, Inc.: Hoboken, NJ, USA, 2011; pp. 261-307.

8. Stone, A. The Theory of Intermolecular Forces; Oxford University Press: Oxford, UK, 2013.

9. Wagner, J.P.; Schreiner, P.R. London Dispersion in Molecular Chemistry-Reconsidering Steric Effects. Angew. Chem. Int. Ed. 2015, 54, 12274-12296. [CrossRef] [PubMed]

10. Minaev, B.F.; Panchenko, A.A. New Aspects of the Airglow Problem and Reactivity of the Dioxygen Quintet $\mathrm{O}_{2}\left({ }^{5} \mathrm{\Pi g}\right) \mathrm{State}$ in the MLT Region as Predicted by DFT Calculations. J. Phys. Chem. A 2020, 124, 9638-9655. [CrossRef]

11. Hayashi, M.; Ohshima, Y. Quantum Tunneling of a He Atom above and below a Benzene Ring. J. Phys. Chem. Lett. 2020, 11, 9745-9750. [CrossRef] [PubMed]

12. Arunan, E.; Emilsson, T.; Gutowsky, H.S. Rotational spectra and structures of Rg-C6H6-H $2 \mathrm{O}$ trimers and the Ne-C6H6 dimer (Rg = Ne, Ar, or Kr). J. Chem. Phys. 1994, 101, 861-868. [CrossRef]

13. Brupbacher, T.; Makarewicz, J.; Bauder, A. Intermolecular dynamics of benzene-rare gas complexes as derived from microwave spectra. J. Chem. Phys. 1994, 101, 9736-9746. [CrossRef]

14. Brupbacher, T.; Bauder, A. Rotational spectrum and dipole moment of the benzene-argon van der Waals complex. Chem. Phys. Lett. 1990, 173, 435-438. [CrossRef]

15. Klots, T.D.; Emilsson, T.; Gutowsky, H.S. Rotational spectra, structure, $\mathrm{Kr}-83$ nuclear quadrupole coupling constant, and the dipole moment of the Kr-benzene dimer. J. Chem. Phys. 1992, 97, 5335-5340. [CrossRef]

16. Tanjaroon, C.; Jäger, W. High-resolution microwave spectrum of the weakly bound helium-pyridine complex. J. Chem. Phys. 2007, 127, 034302. [CrossRef]

17. Maris, A.; Caminati, W.; Favero, P.G. Bond energy of complexes of neon with aromatic molecules: Rotational spectrum and dynamics of pyridine-neon. Chem. Commun. 1998, 2625-2626. [CrossRef]

18. Evangelisti, L.; Favero, L.B.; Giuliano, B.M.; Tang, S.; Melandri, S.; Caminati, W. Microwave Spectrum of $[1,1]-$ Pyridine-Ne $_{2}$. J Phys. Chem. A 2009, 113, 14227-14230. [CrossRef]

19. Melandri, S.; Giuliano, B.M.; Maris, A.; Evangelisti, L.; Velino, B.; Caminati, W. Rotational Spectrum of the Mixed van der Waals Triad Pyridine-Ar-Ne. ChemPhysChem 2009, 10, 2503-2507. [CrossRef] [PubMed]

20. Velino, B.; Caminati, W. Fourier transform microwave spectrum of pyridine-neon. J. Mol. Spectrosc. 2008, 251, 176-179. [CrossRef]

21. Klots, T.D.; Emilsson, T.; Ruoff, R.S.; Gutowsky, H.S. Microwave spectra of noble gas-pyridine dimers: Argon-pyridine and krypton-pyridine. J. Phys. Chem. 1989, 93, 1255-1261. [CrossRef]

22. Melandri, S.; Maccaferri, G.; Maris, A.; Millemaggi, A.; Caminati, W.; Favero, P.G. Observation of the rotational spectra of van der Waals complexes by free jet absorption millimeter wave spectroscopy: Pyridine-argon. Chem. Phys. Lett. 1996, 261, 267-271. [CrossRef]

23. Caminati, W.; Favero, P.G. Chemistry at Low Pressure and Low Temperature: Rotational Spectrum and Dynamics of PyrimidineNeon. Chem. Eur. J. 1999, 5, 811-814. [CrossRef]

24. Caminati, W.; Favero, P.G.; Melandri, S.; Meyer, R. Free jet absorption millimeter wave spectrum of the pyrimidine-argon molecular complex. Chem. Phys. Lett. 1997, 268, 393-400. [CrossRef]

25. Caminati, W.; Melandri, S.; Dell'Erba, A.; Favero, P.G. Bonding energies of rare gases with aromatic molecules: Rotational spectrum and dynamics of pyridazine $\cdots$ neon. PhysChem Comm 2000, 3, 1-4. [CrossRef]

26. Caminati, W.; Millemaggi, A.; Favero, P.G.; Makarewicz, J. Free jet absorption millimeter wave spectrum and van der Waals potential energy surface of the pyridazine-argon adduct. J. Phys. Chem. A 1997, 101, 9272-9275. [CrossRef]

27. Stahl, W.; Grabow, J.U. The Rotational Spectrum of the Fluorobenzene-Argon Van der Waals Complex. Z. Naturforsch. Sect. A J. Phys. Sci. 1992, 47, 681-684. [CrossRef]

28. Sussmann, R.; Neusser, H.J. The van der Waals rovibronic spectrum of p-difluorobenzene-Ar up to $125 \mathrm{~cm}^{-1}$ intermolecular energy: Assignment and character of van der Waals modes. J. Chem. Phys. 1995, 102, 3055-3063. [CrossRef]

29. Jayasekharan, T.; Parmenter, C.S. Characteristics and relaxation dynamics of van der Waals complexes between p-difluorobenzene and Ne. J. Chem. Phys. 2004, 120, 11469-11478. [CrossRef]

30. Sun, M.; Kamaee, M.; Van Wijngaarden, J. Rotational spectra and structures of the van der waals dimers of argon with 2fluoropyridine and 3-fluoropyridine. J. Phys. Chem. A 2013, 117, 13429-13434. [CrossRef]

31. Bettens, R.P.A.; Spycher, R.M.; Bauder, A. Intermolecular force field and approximate equilibrium structure of various complexes containing one or two rare gas atoms from microwave spectroscopic constants. Mol. Phys. 1995, 86, 487-511. [CrossRef]

32. Evangelisti, L.; Brendel, K.; Mäder, H.; Caminati, W.; Melandri, S. Rotational Spectroscopy Probes Water Flipping by Full Fluorination of Benzene. Angew. Chem. Int. Ed. 2017, 56, 13699-13703. [CrossRef]

33. Calabrese, C.; Gou, Q.; Maris, A.; Caminati, W.; Melandri, S. Probing the Lone Pair- $\pi$-Hole Interaction in Perfluorinated Heteroaromatic Rings: The Rotational Spectrum of Pentafluoropyridine-Water. J. Phys. Chem. Lett. 2016, 7, 1513-1517. [CrossRef] [PubMed]

34. Li, W.; Usabiaga, I.; Calabrese, C.; Evangelisti, L.; Maris, A.; Favero, L.B.; Melandri, S. Characterizing the lone pair $\cdots \pi-$ hole interaction in complexes of ammonia with perfluorinated arenes. Phys. Chem. Chem. Phys. 2021, 23, 9121-9129. [CrossRef] [PubMed] 
35. López, J.C.; Macario, A.; Maris, A.; Alkorta, I.; Blanco, S. How Aromatic Fluorination Exchanges the Interaction Role of Pyridine with Carbonyl Compounds: The Formaldehyde Adduct. Chem. Eur. J. 2021, 27, 13870-13878. [CrossRef]

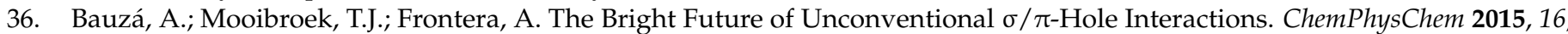
2496-2517. [CrossRef]

37. Alkorta, I.; Rozas, I.; Elguero, J. An Attractive Interaction between the $\pi$-Cloud of C6F6 and Electron-Donor Atoms. J. Org. Chem. 1997, 62, 4687-4691. [CrossRef]

38. Gallivan, J.P.; Dougherty, D.A. Can Lone Pairs Bind to a $\pi$ System? The Water $\cdots$ Hexafluorobenzene Interaction. Org. Lett. 1999, 1 , 103-106. [CrossRef] [PubMed]

39. Alkorta, I.; Rozas, I.; Elguero, J. Interaction of Anions with Perfluoro Aromatic Compounds. J. Am. Chem. Soc. 2002, 124, 8593-8598. [CrossRef]

40. Quiñonero, D.; Garau, C.; Rotger, C.; Frontera, A.; Ballester, P.; Costa, A.; Deyà, P.M. Anion- $\pi$ Interactions: Do They Exist? Angezw. Chem. Int. Ed. 2002, 41, 3389-3392. [CrossRef]

41. Frontera, A.; Gamez, P.; Mascal, M.; Mooibroek, T.J.; Reedijk, J. Putting Anion- $\pi$ Interactions Into Perspective. Angez. Chem. Int. Ed. 2011, 50, 9564-9583. [CrossRef] [PubMed]

42. Mascal, M.; Armstrong, A.; Bartberger, M.D. Anion-aromatic bonding: A case for anion recognition by $\pi$-acidic rings. J. Am. Chem. Soc. 2002, 124, 6274-6276. [CrossRef]

43. Pickett, H.M. The fitting and prediction of vibration-rotation spectra with spin interactions. J. Mol. Spectrosc. 1991, 148, 371-377. [CrossRef]

44. Watson, J.K.G. Aspects of Quartic and Sextic Centrifugal Effects on Rotational Energy Levels. In Vibrational Spectra and Structure a Series of Advances; Durig, J.R., Ed.; Elsevier: New York, NY, USA, 1977; Volume 6, pp. 1-89.

45. Gordy, W.; Cook, R.L. Microwave Molecular Spectra; Wiley-Interscience: New York, NY, USA, 1984; Volume 11, ISBN 0471086819.

46. Doraiswamy, S.; Sharma, S.D. Microwave spectrum, centrifugal distortion constants, dipole moment and quadrupole coupling constants of pentafluoropyridine. Chem. Phys. 1974, 6, 76-86. [CrossRef]

47. Kraitchman, J. Determination of Molecular Structure from Microwave Spectroscopic Data. Am. J. Phys. 1953, 21, 17-24. [CrossRef]

48. van Eijck, B.P. Influence of molecular vibrations on substitution coordinates. J. Mol. Spectrosc. 1982, 91, 348-362. [CrossRef]

49. Kisiel, Z. Least-squares mass-dependence molecular structures for selected weakly bound intermolecular clusters. J. Mol. Spectrosc. 2003, 218, 58-67. [CrossRef]

50. Watson, J.K.; Roytburg, A.; Ulrich, W. Least-Squares Mass-Dependence Molecular Structures. J. Mol. Spectrosc. 1999, 196, 102-119. [CrossRef] [PubMed]

51. Stephens, P.J.; Devlin, F.J.; Chabalowski, C.F.; Frisch, M.J. Ab Initio calculation of vibrational absorption and circular dichroism spectra using density functional force fields. J. Phys. Chem. 1994, 98, 11623-11627. [CrossRef]

52. Grimme, S.; Antony, J.; Ehrlich, S.; Krieg, H. A consistent and accurate ab initio parametrization of density functional dispersion correction (DFT-D) for the 94 elements H-Pu. J. Chem. Phys. 2010, 132, 154104. [CrossRef] [PubMed]

53. Grimme, S.; Ehrlich, S.; Goerigk, L. Effect of the damping function in dispersion corrected density functional theory. J. Comput. Chem. 2011, 32, 1456-1465. [CrossRef]

54. Møller, C.; Plesset, M.S. Note on an approximation treatment for many-electron systems. Phys. Rev. 1934, 46, 618-622. [CrossRef]

55. Frisch, M.J.; Pople, J.A.; Binkley, J.S. Self-consistent molecular orbital methods 25. Supplementary functions for Gaussian basis sets. J. Chem. Phys. 1984, 80, 3265-3269. [CrossRef]

56. Blanco, S.; Pinacho, P.; López, J.C. Hydrogen-Bond Cooperativity in Formamide 2-Water: A Model for Water-Mediated Interactions Angew. Chem. Int. Ed. 2016, 55, 9331-9335. [CrossRef]

57. Kendall, R.A.; Dunning, T.H.; Harrison, R.J. Electron affinities of the first-row atoms revisited. Systematic basis sets and wave functions. J. Chem. Phys. 1992, 96, 6796-6806. [CrossRef]

58. Scuseria, G.E.; Janssen, C.L.; Schaefer, H.F. An efficient reformulation of the closed-shell coupled cluster single and double excitation (CCSD) equations. J. Chem. Phys. 1988, 89, 7382-7387. [CrossRef]

59. Frisch, M.J.; Frisch, M.J.; Trucks, M.J.; Schlegel, H.B.; Scuseria, G.E.; Robb, M.A.; Cheeseman, J.R.; Scalmani, G.; Barone, V.; Petersson, G.A.; et al. Gaussian 16, Revision, A.03; Gaussian Inc.: Wallingford, CT, USA, 2016.

60. Jansen, G.; Hesselmann, A.; Williams, H.L.; Chabalowski, C.F. Comment on "using Kohn-Sham orbitals in symmetry-adapted perturbation theory to investigate intermolecular interactions". J. Phys. Chem. A 2001, 105, 11156-11157. [CrossRef]

61. Hesselmann, A. DFT-SAPT Intermolecular Interaction Energies Employing Exact-Exchange Kohn-Sham Response Methods. J. Chem. Theory Comput. 2018, 14, 1943-1959. [CrossRef]

62. Werner, H.J.; Knowles, P.J.; Manby, F.R.; Black, J.A.; Doll, K.; Heßelmann, A.; Kats, D.; Köhn, A.; Korona, T.; Kreplin, D.A.; et al. The Molpro quantum chemistry package. J. Chem. Phys. 2020, 152, 144107. [CrossRef]

63. Adamo, C.; Barone, V. Toward reliable density functional methods without adjustable parameters: The PBE0 model. J. Chem. Phys. 1999, 110, 6158-6170. [CrossRef]

64. Bader, R.F.W. A quantum theory of molecular structure and its applications. Chem. Rev. 1991, 91, 893-928. [CrossRef]

65. Contreras-García, J.; Johnson, E.R.; Keinan, S.; Chaudret, R.; Piquemal, J.P.; Beratan, D.N.; Yang, W. NCIPLOT: A program for plotting noncovalent interaction regions. J. Chem. Theory Comput. 2011, 7, 625-632. [CrossRef]

66. Brown, G.G.; Dian, B.C.; Douglass, K.O.; Geyer, S.M.; Shipman, S.T.; Pate, B.H. A broadband Fourier transform microwave spectrometer based on chirped pulse excitation. Rev. Sci. Instrum. 2008, 79, 053103. [CrossRef] [PubMed] 
67. Pinacho, P.; Blanco, S.; López, J.C. The complete conformational panorama of formanilide-water complexes: The role of water as a conformational switch. Phys. Chem. Chem. Phys. 2019, 21, 2177-2185. [CrossRef] [PubMed]

68. Balle, T.J.; Flygare, W.H. Fabry-Perot cavity pulsed Fourier transform microwave spectrometer with a pulsed nozzle particle source. Rev. Sci. Instrum. 1981, 52, 33-45. [CrossRef]

69. Alonso, J.; Lorenzo, F.J.; López, J.C.; Lesarri, A.; Mata, S.; Dreizler, H. Construction of a molecular beam Fourier transform microwave spectrometer used to study the 2,5-dihydrofuran-argon van der Waals complex. Chem. Phys. 1997, 218, 267-275. [CrossRef] 